\title{
GEOGRAPHIC POVERTY TRAPS? A MICRO MODEL OF CONSUMPTION GROWTH IN RURAL CHINA
}

\author{
JYOTSNA JALAN ${ }^{a}$ AND MARTIN RAVALLION ${ }^{\text {** }}$ \\ a Indian Statistical Institute New Delhi, 110 016, INDIA \\ ${ }^{\mathrm{b}}$ World Bank, Washington, DC 20433, USA
}

\section{SUMMARY}

How important are neighbourhood endowments of physical and human capital in explaining diverging fortunes over time for otherwise identical households in a developing rural economy? To answer this question we develop an estimable micro model of consumption growth allowing for constraints on factor mobility and externalities, whereby geographic capital can influence the productivity of a household's own capital. Our statistical test has considerable power in detecting geographic effects given that we control for latent heterogeneity in measured consumption growth rates at the micro level. We find robust evidence of geographic poverty traps in farm-household panel data from post-reform rural China. Our results strengthen the equity and efficiency case for public investment in lagging poor areas in this setting. Copyright (c) 2002 John Wiley $\&$ Sons, Ltd.

\section{INTRODUCTION}

Persistently poor areas have been a concern in many countries, including those undergoing sustained aggregate economic growth. A casual observer travelling widely around present-day China will be struck by the disparities in levels of living, and signs that the robust growth of relatively well-off coastal areas has not been shared by poor areas inland, such as in the southwest. China is not unusual; most countries have geographic concentrations of poverty; other examples are the eastern islands of Indonesia, northeastern India, northwestern Bangladesh, northern Nigeria, southeast Mexico and northeast Brazil.

Why do we see areas with persistently low living standards, even in growing economies? One view is that they arise from persistent spatial concentrations of individuals with personal attributes which inhibit growth in their living standards. This view does not ascribe a causal role to geography per se; otherwise identical individuals will (by this view) have the same growth prospects independently of where they live.

Alternatively one might argue that geography has a causal role in determining how household welfare evolves over time. By this view, geographic externalities arising from local public goods, or local endowments of private goods, entail that living in a well-endowed area means that a poor household can eventually escape poverty. Yet an otherwise identical household living in a poor area sees stagnation or decline. If this is so, then it is important for policy to understand what geographic factors matter to growth prospects at the micro level.

\footnotetext{
* Correspondence to: Martin Ravallion, World Bank (MSN 3-306), 1818 H Street HW, Washington, DC 20433, USA. E-mail: mravallion@worldbank.org

Contract/grant sponsor: World Bank’s Research Committee; Contract/grant number: RPO 681-39.
} 
This paper tests for the existence of 'geographic poverty traps', such that characteristics of a household's area of residence - its 'geographic capital' — entail that the household's consumption cannot rise over time, while an otherwise identical household living in a better-endowed area enjoys a rising standard of living. The paper also tries to identify the factors which may lead to the emergence of such poverty traps. If borne out by empirical evidence, geographic poverty traps suggest both efficiency and equity arguments for investing in poor areas, such as by developing local infrastructure or by assisting labour export to better-endowed areas.

The setting for our empirical work is post-reform rural China and we study the determinants of consumption growth for farm households. We can rule out potential endogeneity due to people choosing their locations because there was little or no geographic mobility of labour in rural China at the time. Governmental restrictions on migration within China are part of the reason. ${ }^{1}$ But there are other constraints on mobility. It is well known that household-level ties to the village associated with traditional social security arrangements in underdeveloped rural economies can be a strong disincentive against migration (see, for example, Das Gupta, 1987, writing about rural India). Thin land markets, and the prospects for administrative reallocation of land, compound the difficulties in rural China. For these reasons, it is unusual for an entire household to move from one rural area to another; the limited migration that is observed in rural China and elsewhere appears to be mainly the temporary export of labour surpluses, primarily to urban areas. Capital is probably more mobile than labour in China, although (again in common with other developing economies) borrowing constraints appear to be pervasive, and financial markets are poorly developed.

One should not be surprised to find geographic differences in living standards in this setting. ${ }^{2}$ Restrictions on labour mobility are one reason. But geography could also have a deeper causal role in the dynamics of poverty in this setting. If geographic externalities alter returns to private investment, and borrowing constraints limit capital mobility, then poor areas can self-perpetuate. Even with diminishing returns to private capital, poor areas will see low growth rates, and possibly contraction.

However, testing for geographic poverty traps poses a number of problems. Using aggregate geographic data, we can test for divergence, whereby poorer areas grow at lower rates. But this is neither necessary nor sufficient for the existence of a geographic poverty trap. Divergence may reflect either increasing returns to individual wealth or geographic externalities, whereby living in a poor area lowers returns to individual investments. Aggregate geographic data cannot distinguish between the two causes.

Alternatively, cross-sectional micro data might be used to test for geographic effects on living standards at one point in time. ${ }^{3}$ Such data can at best provide a snapshot of a household's welfare. One cannot say with statistical conviction that the observed geographic effects are not in fact proxies for some unobserved household variables.

Both household panel data and geographic data are clearly called for to have any hope of identifying geographic externalities in the growth process. But how should such data be modelled?

\footnotetext{
${ }^{1}$ There are various administrative and other restrictions on migration, including registration and residency requirements. For example, it appears to be rare for a rural worker who moves to an urban area to be allowed to enroll his or her children in the urban schools.

${ }^{2}$ For evidence on China's regional disparities see Leading Group (1988), Lyons (1991), Tsui (1991), World Bank (1992, 1997), Knight and Song (1993), Rozelle (1994), Howes and Hussain (1994) and Ravallion and Jalan (1996). On implications for policy (in the light of the results of the present paper) see Ravallion and Jalan (1999).

${ }^{3}$ See Borjas (1995) on neighbourhood effects on schooling and wages in the USA and Ravallion and Wodon (1999) on geographic effects on the level of poverty in Bangladesh.
} 
One might turn to the standard panel data model with time-invariant household fixed effects. Allowing for latent heterogeneity in the household-level growth process will protect against spurious geographic effects that arise from omitted geographic effects (such as latent factors in the placement of government programmes) or omitted non-geographic, but spatially autocorrelated, household characteristics. ${ }^{4}$ However, standard panel-data techniques-like first-differencing the data to eliminate the correlated unobserved household specific effects-wipe out any hope of identifying impacts of the time-invariant geographic variables of interest, of which there are likely to be many. ${ }^{5}$ In that case, the cure to the problem of latent heterogeneity leaves an econometric model which is unable to answer many of the questions we started out with. Nor, for that matter, is it obviously plausible that the heterogeneity in individual effects on growth rates would in fact be time invariant; common macroeconomic and geo-climatic conditions might well entail that the individual effects vary from year to year.

We propose an estimable micro model of consumption growth which can identify underlying (including time-invariant) geographic effects while at the same time allowing for latent heterogeneity in household-level growth rates. Our empirical work is motivated by an adaptation of the Ramsey (1928) model of optimal consumption growth. The Ramsey model is modified to allow geographic effects on the marginal product of own capital in the presence of constraints on capital mobility. Our econometric model uses longitudinal observations of growth rates at the micro level collated with other micro and geographic data. Following Holtz-Eakin, Newey and Rosen (1988), our panel data model allows for individual effects with non-stationary impacts. The standard fixed effects model is encompassed as a testable restricted form. If it is rejected in favour of non-stationary effects then we are able to identify impacts of time-invariant geographic capital on consumption growth at micro level while still allowing for latent heterogeneity in measured growth rates. We implement the approach using farm-household panel data for rural areas of southern China over 1985-90.

The following section outlines our theoretical model of consumption growth, while Section 3 gives the econometric model. Section 4 describes our data while Section 5 presents our results. Section 6 summarizes our conclusions.

\section{THEORETICAL MODEL}

Our empirical work is motivated by extending the classic Ramsey model of intertemporal consumer equilibrium to include production by a farm-household facing geographic externalities in its production process. We hypothesize that output of the farm household is a concave function of various privately provided inputs, but that output also depends positively and non-separably on the level of geographic capital, as described by characteristics of the area of residence. ${ }^{6}$ We do not assume perfect capital mobility. In competitive equilibrium, this would entail that marginal

\footnotetext{
${ }^{4}$ For example, suppose that the average wealth of an area is positively correlated with growth rates at household level, controlling for household wealth. This may be because some household attribute relevant to growth, and positively correlated with average wealth, has been omitted. Better own education may yield higher growth rates, be correlated with wealth, and be spatially autocorrelated. Then average wealth in the area of residence could just be proxying for individual education.

${ }^{5}$ Area characteristics (land quality) may be time-invariant. Alternatively, variables like population density are typically only available from population censuses which are done infrequently, and so such variables must also be treated as time-invariant.

${ }^{6}$ Analogously to the role of external (economy-wide) knowledge on firm productivity in the Romer (1986) model.
} 
products of private capital (net of depreciation rates) are equalized across all farm-households at a common rate of interest. Then (under the other assumptions of the standard Ramsey model) differences in endowments of geographic capital will not entail differences in consumption growth rates, even if the geographic differences alter the marginal product of private capital. Levels of private capital will adjust to restore equilibrium. To assume perfect capital mobility would thus preclude what is arguably the main source of the geographic poverty traps that we hope to test for. Although limited financial transactions exist, perfect capital mobility is also implausible in this setting.

The household operates a farm which produces output by combining labour and own capital (which can be interpreted as a composite of land, physical capital and human capital) under constant returns to scale. There are constraints on access to credit, with the effect that capital is not perfectly mobile between farm-households. Thus diminishing returns to private capital set in at the farmhousehold level. The household's farm output also depends on a vector of geographic variables, $G$, reflecting external effects on own-production. Output per worker or person is $F(K, G)$ where $K$ denotes capital per worker. Output can be consumed, invested (including offsets for depreciation), or used to repay debt. We make the standard assumption that the household maximizes an intertemporally additive utility integral:

$$
\int_{0}^{\infty} \frac{1}{1-\sigma} C(t)^{1-\sigma} e^{-\rho t} \mathrm{~d} t
$$

where $\sigma$ is the intertemporal elasticity of substitution, $C$ is consumption, and $\rho$ is the subjective rate of time preference.

The derivation of the optimal rate of consumption growth under these assumptions then follows from standard methods for dynamic optimization. It can be shown that the optimal rate of consumption growth satisfies the Euler equation:

$$
g(t) \equiv \mathrm{d} \ln C(t)=\left[F_{K}(K, G)-\rho-\delta\right] / \sigma
$$

where $\delta$ is the rate of depreciation plus labour augmenting technical progress.

The key feature of this equation for our purpose is that geographic externalities can influence consumption growth rates at the farm-household level, through effects on the marginal product of own capital. The model permits values of $G$ such that the optimal consumption growth rate is negative; given $G$, output gains from individually optimal investments may not be sufficient to cover $\rho+\delta$ and so consumption falls.

There are other ways in which geographic effects on consumption growth might arise, not captured by the above model. For example, we could also allow geographic variables to influence utility at a given level of consumption, by making the substitution parameter and the discount rate functions of $G$. While our empirical model will allow us to test for geographic effects on consumption growth at the micro level it will not allow us to identify the precise mechanism linking area characteristics to growth.

\section{ECONOMETRIC MODEL}

The Euler equation in (2) motivates an empirical model in which the growth rate of household consumption depends on both the household's own capital and on its geographic capital. Data are 
available for a random sample of $N$ households observed over $T$ dates, where $T$ is at least three (for reasons that will soon be obvious). Let $g_{i t}$ denote the expected value of the growth path for $i$ at $t\left(g_{i t}\right.$ is thus the value of $g(t)$ in discrete time) and let $\Delta \ln C_{i t}$ be the measured growth-rate of consumption for household $i$ in time period $t$. Rather than assume that $\Delta \ln C_{i t}=g_{i t}$ we allow for measurement errors and lagged effects according to an ad hoc adjustment model:

$$
\Delta \ln C_{i t}=\gamma \Delta \ln C_{i t-1}+(1-\gamma) g_{i t}+\varepsilon_{i t}(i=1,2, . ., N ; t=4, . ., T)
$$

where $\varepsilon_{i t}$ is an error term. This can be taken to include idiosyncratic effects on the marginal product of own capital and the rate of time preference, as well as measurement errors in growth rates. Our empirical model for $g_{i t}$ is:

$$
g_{i t}=\left(\alpha+\beta x_{i t}+\xi z_{i}\right) /(1-\gamma)
$$

where $x_{i t}$ is a $(k \times 1)$ vector of time-varying explanatory (geographic and household) variables, and $z_{i}$ is a $(p \times 1)$ vector of exogenous time-invariant explanatory (geographic and household) variables.

There are likely to be differences in own-capital endowments, and other parameters of utility and production functions, which one cannot hope to fully capture in the data available. There are also likely to be omitted geographic variables, such as latent political or economic factors influencing the placement of observed governmental programmes. Furthermore, it is likely that these unobserved household and geographic variables will be correlated with the observed geographic variables, leading to biases in OLS estimates of the parameters of interest. So in estimating equation (3), we assume that the error term $\varepsilon_{i t}$ includes a household-specific fixed effect (which may also include unobserved geographic effects) correlated with the regressors as well as an i.i.d. random component which is orthogonal to the regressors and is serially uncorrelated.

The existence of economy-wide factors (including covariate shocks to agriculture) suggests that the impact of the heterogeneity need not be constant over time. For example, there may be a latent effect such that some farmers are more productive, but this matters more in a bad agricultural year than a good one. This could also hold for observed sources of heterogeneity. In particular, some or all of the $z_{i}$ variables may well have time-varying effects, so that $\varepsilon_{i t}$ includes deviations from the time mean impacts, $\left(\xi_{t}-\xi\right) z_{i}$, in obvious notation. This would also entail a correlation between the latent household-specific effect and the regressors, as well as non-stationarity in the latent effects. However, the time-varying parameters $\xi_{t}$ are clearly not identifiable; only time-mean impacts are recoverable.

To allow for non-stationarity in the impacts of the individual effects we follow Holtz-Eakin et al. (1988) in decomposing the composite error term as:

$$
\varepsilon_{i t}=\theta_{t} \omega_{i}+u_{i t}
$$

where $u_{i t}$ is the i.i.d. random variable, with mean 0 and variance $\sigma_{u}^{2}$, and $\omega_{i}$ is a time-invariant effect that is not orthogonal to the regressors. The following assumptions are made about the error structure:

$$
E\left(\omega_{i} x_{i t}\right) \neq 0, E\left(\omega_{i} z_{i}\right) \neq 0, E\left(\omega_{i} u_{i t}\right)=0, E\left(x_{i t} u_{i t}\right)=0, E\left(z_{i} u_{i t}\right)=0 \forall i, t
$$

Since the composite error term $\varepsilon_{i t}$ in equation (5) is not orthogonal to the regressors, estimating (3) by OLS will give inconsistent estimates. Serial independence of $u_{i t}$ is a strong assumption; for 
example, measurement error in the levels of consumption can generate first-order (negative) serial correlation in $u_{i t}$. However, while serial independence of $u_{i t}$ is sufficient for our estimation strategy, it is not necessary; we will perform diagnostic tests on the necessary condition (below).

In standard panel data models, the 'nuisance' variable $\omega_{i}$ is eliminated by estimating the model in first differences or by taking time-mean deviations (when there is no lagged dependent variables in the model). ${ }^{7}$ However, given the temporal pattern of the effect of $\omega_{i}$ on $\Delta \ln C_{i t}$, we cannot use these transformations to eliminate the fixed effect. We use instead quasi-differencing techniques, following Holtz-Eakin et al. (1988). ${ }^{8}$ Substituting equations (4) and (5) into (3) and lagging by one period we get:

$$
\Delta \ln C_{i t-1}=\alpha+\gamma \Delta \ln C_{i t-2}+\beta x_{i t-1}+\xi z_{i}+\theta_{t-1} \omega_{i}+u_{i t-1}
$$

Define $r_{t}=\theta_{t} / \theta_{t-1}$. Multiplying equation (7) by $r_{t}$ and subtracting from equation (3):

$$
\begin{aligned}
\Delta \ln C_{i t}= & \alpha\left(1-r_{t}\right)+\left(\gamma+r_{t}\right) \Delta \ln C_{i t-1}-\gamma r_{t} \Delta \ln C_{i t-2}+\beta\left(x_{i t}-r_{t} x_{i t-1}\right) \\
& +\xi\left(1-r_{t}\right) z_{i}+u_{i t}-r_{t} u_{i t-1}
\end{aligned}
$$

Notice that even if we had assumed that the measured growth rate is the long-run value for that date $(\gamma=0)$, a dynamic specification would still be called for as long as the latent effects are time varying. This is generated by the quasi-differencing.

Consider the identification of the original parameters. Equation (8) is a function of the ratio $r_{t}$ of the coefficients of the individual effects. The level of these coefficients are not identified. Rewriting equation (8) as:

$$
\Delta \ln C_{i t}=a_{t}+b_{t} \Delta \ln C_{i t-1}+c_{t} \Delta \ln C_{i t-2}+d x_{i t}+e_{t} x_{i t-1}+f_{t} z_{i}+v_{i t}
$$

where

$$
\begin{aligned}
a_{t} & =\alpha\left(1-r_{t}\right) \\
b_{t} & =\left(\gamma+r_{t}\right) \\
c_{t} & =-\gamma r_{t} \\
d & =\beta \\
e_{t} & =-\beta r_{t} \\
f_{t} & =\xi\left(1-r_{t}\right) \\
v_{i t} & =u_{i t}-r_{t} u_{i t-1}
\end{aligned}
$$

In our model, the only time-varying parameter is the ratio of the coefficients of the individual effects, $r_{t}$. Thus all the original parameters (excepting the levels of the coefficients associated with the individual effect) can easily be recovered without any further restrictions on the number of estimable time periods.

\footnotetext{
${ }^{7}$ An alternative estimation method is the dynamic random effects estimator developed by Bhargava and Sargan (1982). However, this method assumes that at least some of the time-varying variables are uncorrelated with the unobserved individual specific effect.

${ }^{8}$ Also see Chamberlain (1984) and Ahn and Schmidt (1994) for alternative quasi-differencing transformations. 
For our purposes, an advantage of the above approach over the standard fixed effects set-up is that coefficients on the time-invariant regressors are identified. Intuitively this is achieved by relaxing the usual cross-equation restrictions that the coefficients on the time-invariant variables must be constant over time. Thus our method simultaneously allows us to control for latent heterogeneity while still identifying the impacts of time invariant factors including the geographic variables of interest.

This general specification can be tested against the restriction of the standard fixed-effects model, namely that $\theta_{t}=\theta$ for all $t$. We recognize that standard chi-square asymptotic tests are not applicable in this case since under the null hypothesis, $\mathrm{H}_{0}: r_{t}=1$, the parameters associated with the constant and the time-invariant variables are not identified. We follow a suggestion by Godfrey (1988) (following Davies, 1977, 1987) to test for the presence of non-stationary fixed effects in our data when several parameters vanish under the null hypothesis. We set $\alpha$ and $\zeta$ to some constants $\alpha_{0}$ and $\zeta_{0}$ respectively. When we test the null hypothesis, $\alpha_{0}\left(1-r_{t}\right)=\zeta_{0}\left(1-r_{t}\right)=0$, the statistic $\operatorname{LM}\left(\alpha_{0}, \zeta_{0}\right) \sim \chi^{2}(1)$ whatever the choices of $\left(\alpha_{0}, \zeta_{0}\right)$. Godfrey (1988) states that in small samples, power of this simple test will be a concern but in our case with a cross-sectional sample of 5600 households this is not an issue.

In estimating equation (8) we must allow for the fact that one of the regressors, $\Delta \ln C_{i t-1}$, is correlated with the error term, $u_{i t}-r_{t} u_{i t-1}$ (although the error term is by construction orthogonal to $x_{i t}$ and $z_{i}$ ). One can estimate equation (8) by Generalized Method of Moments (GMM) using differences and/or levels of log consumptions lagged twice (or higher) as instruments for $\Delta \ln C_{i t-1}$. (The Appendix provides a more complete exposition of the estimation method.) The essential condition to justify this choice of instruments is that the error term in (8) is second-order serially independent. That is implied by serial independence of $u_{i t} .{ }^{9}$

To ensure that our estimation strategy is valid we perform three diagnostic tests. First, we test whether latent individual-specific effects are present in our data. We construct a Hausman-type test where the null hypothesis that the GLS model is the correct one is tested against the latent variable model. Second, we follow Arellano and Bond (1991) in constructing an overidentification test to ensure that our instruments are consistent with the data and are indeed exogenous. Third, we perform the Arellano-Bond second-order serial correlation test, given that the consistency of the GMM estimators for the quasi-differenced model depends on the assumption that the composite error term in (8) is second-order serially independent, as discussed above. ${ }^{10}$ Lack of secondorder serial correlation and the non-rejection of the overidentification test support our choice of instruments.

Note also that quasi-differencing the data to eliminate the unobserved household effects will also remove any remaining latent geographic effects provided the $r_{t}$ 's are the same for the countyand the individual-specific effects. However, this need not be the case in our data. To test against the presence of remaining latent area effects, we regressed the estimated residuals against a set of geographic dummies and tested their joint significance.

\footnotetext{
${ }^{9}$ There is some debate regarding the choice of the optimal moment conditions (and hence instruments) to estimate dynamic panel data models efficiently (Ahn and Schmidt, 1995; Blundell and Bond, 1997). In this discussion, the primary concern is with respect to the use of lagged level instruments especially in cases where the estimated coefficient of the lagged dependent variable is close to unity. In a related paper, Binder, Hsiao and Pesaran (2000) suggest a maximum likelihood estimator to circumvent the problem of unit-roots in short panels. Their methods however, can not be easily extended to the GMM framework. In our case, the estimable model is in differences. Further, the coefficient estimate for the lagged difference dependent variable is different from unity.

${ }^{10}$ Note that there is some first-order serial correlation introduced in the model due to the quasi-differencing. This means that log consumptions lagged once are not valid instruments.
} 


\section{DATA}

The farm-household level data were obtained from China's Rural Household Survey (RHS) done by the State Statistical Bureau (SSB). A panel of 5600 farm households over the six-year period 1985-90 was formed for four contiguous provinces in southern China, namely Guangdong, Guangxi, Guizhou, and Yunnan. The latter three provinces form southwest China, widely regarded as one of the poorest regions in the country. Guangdong on the other hand is a relatively prosperous coastal region (surrounding Hong Kong). In 1990, 37\%, 42\% and 34\% of the populations of Guangxi, Guizhou and Yunnan, respectively, fell below an absolute poverty line which only 5\% of the population of Guangdong could not afford (Chen and Ravallion, 1996). Also the rural southwest appears to have shared little in China's national growth in the 1980s. For the full sample over 1985-90, consumption per person grew at an average rate of only $0.70 \%$ per annum; for Guangdong, however, the rate of growth was 3.32\%. Between 1985 and 1990, 54\% of the sampled households saw their consumption per capita increase while the rest experienced decline.

The data appear to be of good quality. Since 1984 the RHS has been a well-designed and executed survey of a random sample of households in rural China (including small-medium towns), with unusual effort made to reduce non-sampling errors (Chen and Ravallion, 1996). Sampled households fill in a daily diary on expenditures and are visited on average every two weeks by an interviewer to check the diaries and collect other data. There is also an elaborate system of cross-checking at the local level. The consumption data from such an intensive survey process are almost certainly more reliable than those obtained by the common cross-sectional surveys in which the consumption data are based on recall at a single interview. For the six-year period 1985-90 the survey was also longitudinal, returning to the same households over time. While this was done for administrative convenience (since local SSB offices were set up in each sampled county), the panel can still be formed. ${ }^{11}$

The consumption measure includes imputed values for consumption from own production valued at local market prices, and imputed values of the consumption streams from the inventory of consumer durables (Chen and Ravallion, 1996). Poverty lines designed to represent the cost at each year and in each province of a fixed standard of living were used as deflators. These were based on a normative food bundle set by SSB, which assures that average nutritional requirements are met with a diet that is consistent with Chinese tastes. This food bundle is then valued at provincespecific prices. The food component of the poverty line is augmented with an allowance for non-food goods, consistent with the non-food spending of those households whose food spending is no more than adequate to afford the food component of the poverty line. ${ }^{12}$

The household data were collated with geographic data at three levels: the village, the county, and the province. At village level, we have data on topography (whether the village is on plains, or in hills or mountains, and whether it is in a coastal area), urbanization (whether it is a rural or suburban area), ethnicity (whether it is a minority group village), whether or not it is a border area (three of the four provinces are at China's external border), and whether the village is in a revolutionary base area (areas where the Communist Party had established its bases prior to

\footnotetext{
${ }^{11}$ Constructing the panel from the annual RHS survey data proved to be more difficult than expected since the identifiers could not be relied upon. Fortunately, virtually ideal matching variables were available in the financial records, which gave both beginning and end of year balances. The relatively few ties by these criteria could easily be broken using demographic (including age) data.

${ }^{12}$ For further details on the poverty lines see Chen and Ravallion (1996). Note that our test for omitted geographic effects can be interpreted as a test for mismeasurement in our deflators. 
1949). At the county level we have a much larger data base drawn from County Administrative Records (from the county statistical year books for 1985-90) and from the 1982 Census. ${ }^{13}$ These cover agriculture (irrigated area, fertilizer usage, agricultural machinery in use), population density, average education levels, rural non-farm enterprises, road density, health indicators, and schooling indicators. At the province level, we simply include dummy variables for the province. All nominal values are normalized to 1985 prices.

The survey data also allow us to measure a number of household characteristics. A composite measure of household wealth can be constructed, comprising valuations of all fixed productive assets, cash, deposits, housing, grain stock, and consumer durables. We also have data on agricultural inputs used, including landholding. To allow for differences in the quality and quantity of family labour (given that labour markets are thin in this setting) we let education and demographics influence the marginal product of own capital; these may also influence the rates of intertemporal substitution and/or time preference. We have data on the size and demographic compositions of the households, and levels of schooling. Table I gives descriptive statistics on the variables.

\section{RESULTS}

We begin with a simple specification in which the only explanatory variables are initial wealth per capita, both at household and county levels. This model is too simple to be believed, but it will help as an expository device for understanding a richer model later.

\subsection{A Simple Expository Model}

Suppose that the only two variables that matter to the long-run consumption growth rate are initial household wealth per capita $(H W)$ and mean wealth per capita in the county of residence $(C W)$. The long-run growth rate for household $i$ is then:

$$
g\left(H W_{i}, C W_{i}\right) \equiv\left(\alpha+\xi^{c} \ln C W_{i}+\xi^{h} \ln H W_{i}\right) /(1-\gamma)
$$

This is embedded in the dynamic empirical model, as described in Section 3.

Using lagged first differences of log consumption as instruments, the GMM estimate of this model gives $r_{t}$ values of $0.601,0.220$, and 0.558 for 1988 to 1990 respectively. Using standard errors which are robust to any cross-sectional heteroscedasticity that might be present in the data, the corresponding $t$-ratios are 7.84, 8.40 and 6.63. The estimated equation for the balanced growth rate is $(t$-ratios in parentheses, also based on robust standard errors):

$$
g(H W, C W)=\underset{(6.02)}{-0.278}-\underset{(4.52)}{0.0221} \ln H W+\underset{(7.27)}{0.0602} \ln C W) / \underset{(57.46)}{1.172}
$$

This is interpretable as the estimate of equation (2) implied by this specification, where $H W$ is interpreted as a measure of $K$ and $C W$ as a measure of $G$.

\footnotetext{
${ }^{13}$ While the county administrative records and the county yearbooks cover rural areas separately, the census county data does not distinguish between the rural and urban areas. However, given that the objective of including the county characteristics is to proxy for the initial level of progress in a particular county relative to another, the aggregate county indicators should be reliable indicators for the differences in socio-economic conditions across the counties. 
Table I. Descriptive statistics

\begin{tabular}{|c|c|c|}
\hline \multirow[t]{2}{*}{ Variable } & \multicolumn{2}{|c|}{ Summary statistics } \\
\hline & Mean & Standard deviation \\
\hline \multicolumn{3}{|l|}{ Dependent variable } \\
\hline Average $\%$ growth rate of consumption, 1986-90 & 0.7004 & 28.5290 \\
\hline \multicolumn{3}{|l|}{ Geographic variables } \\
\hline Proportion of sample in Guangdong & 0.2286 & 0.4199 \\
\hline Proportion of sample in Guangxi & 0.2442 & 0.4296 \\
\hline Proportion of sample in Yunnan & 0.2029 & 0.4021 \\
\hline Proportion living in a revolutionary base area & 0.0259 & 0.1587 \\
\hline $\begin{array}{l}\text { Proportion of counties sharing a border with a foreign } \\
\text { country }\end{array}$ & 0.1547 & 0.3616 \\
\hline Proportion of villages located on the coast & 0.0307 & 0.1724 \\
\hline $\begin{array}{l}\text { Proportion of villages in which there is a concentration of } \\
\text { ethnic minorities }\end{array}$ & 0.2562 & 0.4365 \\
\hline Proportion of villages that have a mountainous terrain & 0.4415 & 0.4966 \\
\hline Proportion of villages located in the plains & 0.2171 & 0.4122 \\
\hline Fertilizers used per cultiv. area (tonnes per $\mathrm{km}^{2}$ ) & 11.8959 & 6.4937 \\
\hline Farm machinery used per capita (horsepower) & 158.5453 & 151.2195 \\
\hline Cultivated area per 10000 persons $\left(\mathrm{km}^{2}\right)$ & 13.0603 & 3.2622 \\
\hline Population density (log) & 8.2264 & 0.3786 \\
\hline Proportion of illiterates in the $15^{+}$population $(\%)$ & 34.8417 & 15.8343 \\
\hline Infant mortality rate (per 1000 live births) & 40.4600 & 23.3683 \\
\hline Medical personnel per 10,000 persons & 8.0576 & 5.0205 \\
\hline $\begin{array}{l}\text { Pop. employed in commercial (non-farm) enterprises (per } \\
10000 \text { persons) }\end{array}$ & 117.8102 & 68.8162 \\
\hline Kilometers of roads per 10000 persons & 14.1900 & 10.4020 \\
\hline Proportion of population living in the urban areas & 0.1018 & 0.0810 \\
\hline \multicolumn{3}{|l|}{ Household-level variables } \\
\hline $\begin{array}{l}\text { Expenditure on agricultural inputs (fertilizers and pesticides) } \\
\text { per cultivated area (yuan per mu) }\end{array}$ & 30.4597 & 80.5274 \\
\hline Fixed productive assets per capita (yuan per capita) & 132.1354 & 217.5793 \\
\hline Cultivated land per capita (mu per capita) ${ }^{\mathrm{a}}$ & 1.2294 & 1.1011 \\
\hline Household size $(\log )$ & 1.6894 & 0.3461 \\
\hline Age of the household head & 42.1315 & 11.4225 \\
\hline $\mathrm{Age}^{2}$ of the household head & 1905.5300 & 1024.7320 \\
\hline Proportion of adults in the household who are illiterate & 0.3230 & 0.2898 \\
\hline $\begin{array}{l}\text { Proportion of adults in the household with primary school } \\
\text { education }\end{array}$ & 0.3819 & 0.3063 \\
\hline $\begin{array}{l}\text { Proportion of children in the household between ages } \\
6-11 \text { years }\end{array}$ & 0.1173 & 0.1408 \\
\hline $\begin{array}{l}\text { Proportion of children in the household between ages } \\
12-14 \text { years }\end{array}$ & 0.0836 & 0.1066 \\
\hline $\begin{array}{l}\text { Proportion of children in the household between ages } \\
15-17 \text { years }\end{array}$ & 0.0698 & 0.1004 \\
\hline Proportion of children with primary school education & 0.2672 & 0.3642 \\
\hline Proportion of children with secondary school education & 0.0507 & 0.1757 \\
\hline $\begin{array}{l}\text { Proportion of a household members working in the state } \\
\text { sector }\end{array}$ & 0.0436 & 0.2042 \\
\hline Proportion of $60^{+}$household members & 0.0637 & 0.1218 \\
\hline
\end{tabular}

Number of households: 5644

Number of counties

Note: $1 \mathrm{mu}=0.000667 \mathrm{~km}^{2}$. 
Thus we find that consumption growth rates at the farm-household level are a decreasing function of own wealth, and an increasing function of average wealth in the county of residence, controlling for latent heterogeneity. We can interpret equation (12) in terms of the model in Section 2. The time preference rate and elasticity of substitution are not identified. Nonetheless, given that the substitution parameter is positive, we can infer from (12) that the marginal product of own capital is decreasing with respect to own capital, but increasing with respect to geographic capital. However, there are other possible interpretations; for example, credit might well be attracted to richer areas, or discount rates might be lower.

Notice that the sum of the coefficients on $\ln C W$ and $\ln H W$ in (12) is positive. Averaging (12) over all households in a given county, we thus find aggregate divergence; counties with higher initial wealth will tend to see higher average growth rates. That is indeed what one finds in aggregate county data for this region of China (Ravallion and Jalan, 1996). This is due entirely to geographic externalities, rather than increasing returns to own wealth at farm-household level.

\subsection{A Richer Model}

While the above specification is useful for expository purposes, we now want to extend the model by adding a richer set of both geographic and household-level variables. Table I gives the descriptive statistics of the explanatory variables to be used in the extended specification.

We first estimated a first-order dynamic consumption growth model as indicated by equation (3). However, the Wald statistic to test the significance of the coefficient associated with the lagged dependent variable $(\gamma)$ had a $p$-value of 0.39 . So we opted for the parsimonious model where the dynamics are introduced only via the quasi-differencing. An advantage of this is that we gain an extra period for the estimation.

Table II reports our GMM estimates of the extended model. On testing the fixed effects model against a model with no latent effects (stationary or non-stationary), a Hausman-type test based on the difference between the quasi-differenced model and the GLS model gave a $\chi_{35}^{2}=63.1$ which is significant at the 5\% level. ${ }^{14}$ Again the conventional fixed effects model is firmly rejected in favour of the specification with time-varying coefficients. ${ }^{15}$ This also means that we can estimate the impacts of the time-invariant geographic (and non-geographic) variables.

Our model also includes time-varying household variables (Table I). The question arises as to whether to treat these variables as exogenous or endogenous. The model where the household variables are treated as exogenous was summarily rejected in favour of the model where the timevarying household variables are endogenous. ${ }^{16}$ Hence, Table II reports estimates where the timevarying household variables are treated as endogenous. All the time-invariant variables-county and household—are treated as exogenous. ${ }^{17}$

\footnotetext{
${ }^{14}$ Given that our preferred estimated equation is static, we can construct a Hausman-type test because the parameter estimates are consistent under both the null and the alternative hypothesis. In our specification we can also simply test the null hypothesis of $r_{t}=0$ for all $t$ which is also rejected by a Wald test.

15 The null hypothesis $\alpha_{0}\left(1-r_{t}\right)=\xi_{0}\left(1-r_{t}\right)=0$ for all $t$, where $\alpha, \xi$ are set to their estimated values, is rejected by a Wald test with a $p$-value of 0.035 for the associated Chi-square statistic.

${ }^{16}$ We estimated a model where the household variables were assumed to be exogenous (base model). Next we estimated an alternative model where it was assumed that the time-varying household variables are endogenous, for which we used lagged values of the endogenous variables as instruments. We then constructed likelihood ratio tests to test the base model against this model (Hall, 1993; Ogaki, 1993).

${ }^{17}$ Even though we include a number of time-invariant household variables as regressors in the model, the correlation matrix associated with these variables indicate the highest correlation to be around 0.7 , suggesting that multi-collinearity is not a serious problem in our sample and model.
} 
Table II. Estimates of the consumption growth model

\begin{tabular}{|c|c|c|}
\hline & \multicolumn{2}{|c|}{ GMM estimates } \\
\hline & Coefficient & $t$-ratio \\
\hline Constant & -0.2723 & $-3.1697^{*}$ \\
\hline \multicolumn{3}{|l|}{ Time-varying fixed effects } \\
\hline$r_{87}$ & 0.0429 & 1.4876 \\
\hline$r_{88}$ & 0.1920 & $5.3425^{*}$ \\
\hline$r_{89}$ & 0.0126 & 0.4776 \\
\hline$r_{90}$ & 0.3690 & $9.0738^{*}$ \\
\hline \multicolumn{3}{|l|}{ Geographic variables } \\
\hline Guangdong (dummy) & 0.0019 & 0.3688 \\
\hline Guizhou (dummy) & 0.0233 & $4.5430^{*}$ \\
\hline Yunnan (dummy) & -0.0048 & -0.8196 \\
\hline Revolutionary base area (dummy) & 0.0207 & $2.3962 *$ \\
\hline Border area (dummy) & -0.0030 & -0.6967 \\
\hline Coastal area (dummy) & -0.0099 & -1.1877 \\
\hline Minority area (dummy) & -0.0037 & -1.1051 \\
\hline Mountainous area (dummy) & -0.0071 & $-2.1253^{*}$ \\
\hline Plains (dummy) & 0.0103 & $2.7631^{*}$ \\
\hline Farm machinery usage per capita $(\times 100)$ & 0.0427 & $3.6099^{*}$ \\
\hline Cultivated area per 10000 persons & 0.0010 & 1.2066 \\
\hline Fertilizer used per cultivated area & 0.0017 & $3.7526^{*}$ \\
\hline Population density (log) & 0.0142 & 1.5695 \\
\hline Proportion of illiterates in $15^{+}$population $(\times 100)$ & 0.0135 & 0.7832 \\
\hline Infant mortality rate $(\times 100)$ & -0.0244 & $-2.0525^{*}$ \\
\hline Medical personnel per capita & 0.0010 & $3.5740^{*}$ \\
\hline Prop. of pop. empl. non-farm commerce $(\times 100)$ & 0.0072 & $2.3572^{*}$ \\
\hline Kilometers of roads per capita $(\times 100)$ & 0.0745 & $4.4783^{*}$ \\
\hline Prop. of population living in the urban areas & -0.0163 & -0.7558 \\
\hline \multicolumn{3}{|l|}{ Household-level variables } \\
\hline Expenditure on agricultural inputs per cultivated area $(\times 100)$ & -0.0866 & $-4.7395^{*}$ \\
\hline Fixed productive assets per capita $(\times 1000)$ & 0.0037 & 0.2958 \\
\hline Cultivated land per capita & -0.0090 & -1.5899 \\
\hline Household size (log) & 0.0447 & $6.9717^{*}$ \\
\hline Age of household head & 0.0023 & $2.8483^{*}$ \\
\hline $\mathrm{Age}^{2}$ of household head $(\times 100)$ & -0.0026 & $-2.9626^{*}$ \\
\hline Proportion of adults in the household who are illiterate & 0.0087 & 1.4718 \\
\hline Prop. of adults in the household with primary school education & -0.0028 & -0.5816 \\
\hline Prop. of children in the household between ages $6-11$ years & 0.0359 & $3.9065^{*}$ \\
\hline Prop. of children in the h'hold between ages $12-14$ years & 0.0434 & $3.3199^{*}$ \\
\hline Prop. of children in the h'hold between ages $15-17$ years & 0.0075 & 0.4963 \\
\hline Proportion of children with primary school education $(\times 100)$ & -0.3790 & -0.9674 \\
\hline Proportion of children with secondary school education & 0.0193 & $2.3486^{*}$ \\
\hline Whether a household member works in the state sector (dummy) & -0.0101 & -1.5062 \\
\hline Proportion of $60^{+}$household members & 0.0199 & 1.6839 \\
\hline
\end{tabular}

Note: *Significant at $5 \%$ level or better.

The overidentification test, and the second-order serial correlation test indicate that the instruments used in the GMM estimation are valid. The overidentification test has a $p$-value of 0.9 and the second-order serial correlation test statistic has a $p$-value of 0.5 . Furthermore, there appear to be no remaining latent area effects in the residuals of the estimated model. The $F$-test statistic is $F(101,22474)=0.95$ which is not significant. 
Many of the geographic variables are significant. Living in a mountainous area lowers the long-run rate of consumption growth, while living on the plains raises it ('hills' is the omitted category). Natural conditions for agriculture tend to be better in the plains than mountains or hills. Both of the geographic variables measuring the extent of modernization in agriculture (farm machinery usage per capita and fertilizer usage per acre) have highly significant positive impacts on individual consumption growth rates. The two health-related variables (infant mortality rate and medical personnel per capita) indicate that consumption growth rates at the farm-household level are significantly higher in generally healthier areas. A higher incidence of employment in non-farm commercial enterprises in a geographic area entails a higher growth rate at the household level for those living there. There is a highly significant positive effect of higher road density in an area on consumption growth. Historically favoured 'revolutionary base' areas have higher long-run growth rates controlling for the other variables.

Consistent with the simpler model we started with, there is a strong tendency for the geographic variables to be either neutral or 'divergent', in that households have higher consumption growth rates in better-endowed areas. This suggests that these geographic characteristics tend to increase the marginal product of own capital.

This is in marked contrast to the household-level variables. In addition to allowing for latent farm-household level effects on consumption growth, we included a number of household level characteristics related to land and both physical and human capital endowments. These effects tend to be neutral or convergent. We find that farm-households with higher expenditure on agricultural inputs per unit land area (an indicator of the capital intensity of agriculture) tended to have lower subsequent growth rates. Fixed productive assets per capita do not, however, emerge as significant; it may well be that the density of agricultural inputs is the better indicator of own-farm capital. Among the other household characteristics, there are a number of significant demographic variables; larger and younger households tend to have higher consumption growth rates. This may reflect the thinness of agricultural labour markets in rural China, so that demographics of the household influence the availability of labour for farm work.

\subsection{Do Geographic Poverty Traps Occur within the Bounds of the Data?}

The above results are consistent with geographic poverty traps. But do such traps actually occur within the bounds of these data? In terms of the theoretical model in Section 2, while one might find that higher endowments of geographic capital raise the marginal product of own capital at the farm-household level, it may still be the case that no area has so little geographic capital to entail falling consumption.

To address this issue, consider first our simple model in Section 5.1. The poverty trap level of county wealth can be defined as $C W^{*}$ such that $g\left(H W, C W^{*}\right)=0$ for given $H W$. Figure 1 gives $C W^{*}$ for each value of $H W$. The figure also gives the data points. Clearly there is a large subset of the data for which $C W$ is too low, given $H W$, to permit rising consumption. Consider, for example, two households both with the sample mean of $\ln H W$, which is 6.50 (with a standard deviation of 0.61). From equation (12), $\ln C W^{*}=7.01$ at this level of household wealth. So if one of the two households happens to live in a county with $\ln C W=7.02$ or higher it will see rising consumption over time in expectation, while if the other lives in a county with $\ln C W=7.00$ or lower it will see falling consumption, even though its initial personal wealth is the same.

We can ask the same question for the richer model. We calculate the critical value of each geographic variable at which consumption growth is zero while holding all other (geographic and 


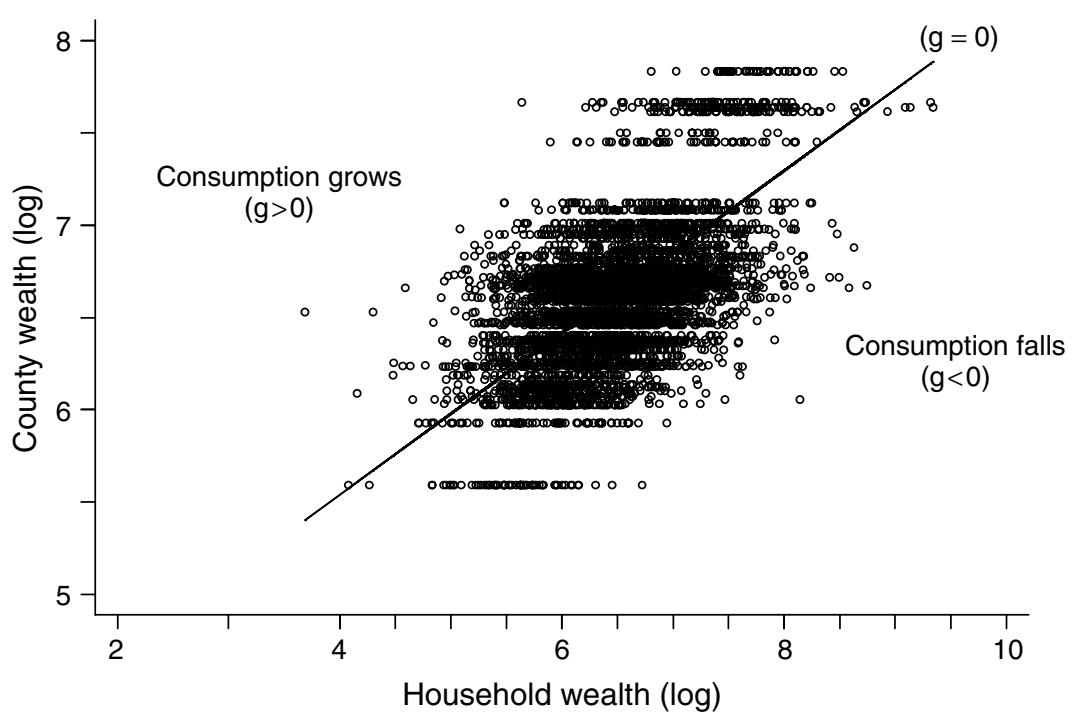

Figure 1. Zero growth combinations of country wealth and household wealth

non-geographic) variables constant. While we cannot graph all the possible combinations in this multidimensional case (as in Figure 1), let us fix other variables at their sample mean values. The critical values implied by our results are given in Table III.

We find, for example, that positive growth in consumption requires that the density of roads exceeds 6.5 square kilometres per 10000 people, with all other variables evaluated at mean points (Table III). In all cases, the critical value at which the geographic poverty trap arises is within one standard deviation of the sample mean for that characteristic.

Geographic poverty traps are clearly well within the bounds of these data.

\section{CONCLUSIONS}

Mapping poverty and its correlates could well be far more than a descriptive tool — it may also hold the key to understanding why poverty persists in some areas, even with robust aggregate growth. That conjecture is the essence of the theoretical idea of a geographic poverty trap. But are such traps of any empirical significance?

That is a difficult question to answer. Aggregate regional growth empirics cannot do so, since aggregation confounds the external effects that create geographic poverty traps with purely internal effects. And, without controlling for latent heterogeneity in the micro growth process, it is hard to accept any test for geographic poverty traps based on micro panel data. In a regression for consumption growth at the household level, significant coefficients on geographic variables may simply pick up the effects of omitted spatially autocorrelated household characteristics. Yet the standard treatments for fixed effects in micro panel-data models make it impossible to identify the impacts of the many time-invariant geographic factors that one might readily postulate as leading to poverty traps. Given the potential policy significance of geographic poverty traps, it is worth searching for a convincing method to test for them. 
Table III. Critical values for a geographic poverty trap

\begin{tabular}{lcc}
\hline Geographic variables & \multicolumn{2}{c}{ Full sample } \\
\cline { 2 - 3 } & $\begin{array}{c}\text { Critical values to } \\
\text { avoid geographic } \\
\text { poverty traps }\end{array}$ & $\begin{array}{c}\text { Sample mean } \\
\text { (standard deviation in } \\
\text { parentheses) }\end{array}$ \\
\hline Fertilizers used per cultivated area (tonnes per km²) & 8.5233 & $\begin{array}{c}11.896 \\
6.494)\end{array}$ \\
Farm machinery used per capita (horsepower) & 2.5209 & 15.855 \\
Infant mortality rate (per 1000 live births) & $63.9573^{*}$ & $\begin{array}{c}11.811) \\
(23.370 .460\end{array}$ \\
Medical personnel per 10000 persons & 2.7977 & 8.058 \\
Population employed in commercial (non-farm) & $5.020)$ \\
enterprises (per 10000 persons) & 38.1804 & 117.810 \\
Kilometers of roads per 10000 persons & & $(68.816)$ \\
\end{tabular}

Notes: A geographic poverty trap will exist if the observed value for any county is less than the critical values given above; for those marked * the observed value cannot exceed the critical value if a poverty trap is to be avoided. Critical values are only reported if the relevant coefficient from Table II is significantly different from zero. All the critical values reported above are significantly different from zero (based on a Wald-type test) at the $5 \%$ level or better.

We have offered a test. This involves regressing consumption growth at the household level on geographic variables, allowing for non-stationary individual effects in the growth rates. By relaxing the restriction that the individual effects have the same impacts at all dates, the resulting dynamic panel-data model of consumption growth allows us to identify external effects of fixed or slowly changing geographic variables.

On implementing the test on a six-year panel of farm-household data for rural areas of southern China, we find strong evidence that a number of indicators of geographic capital have divergent impacts on consumption growth at the micro level, controlling for (observed and unobserved) household characteristics. The main interpretation we offer for this finding is that living in a poor area lowers the productivity of a farm-household's own investments, which reduces the growth rate of consumption, given restrictions on capital mobility.

With only six years of data it would clearly be hazardous to give our findings a 'long-run' interpretation (though six years is relatively long for a household panel). Possibly we are observing a transition period in the Chinese rural economy. However, our results do suggest that there were areas in this part of rural China in this period which were so poor that the consumptions of some households living in them were falling even while otherwise identical households living in better off areas enjoyed rising consumptions. Within the period of analysis, the geographic effects were strong enough to imply poverty traps.

What geographic characteristics create poverty traps? We find that there are publicly provided goods in this setting, such as rural roads, which generate non-negligible gains in living standards. (And since we have allowed for latent geographic effects, the effects of these governmental variables cannot be ascribed to endogenous programme placement.) We also find that the aspects of geographic capital relevant to consumption growth embrace both private and publicly provided 
goods and services. Private investments in agriculture, for example, entail external benefits within an area, as do 'mixed' goods (involving both private and public provisioning) such as health care. The prospects for growth in poor areas will then depend on the ability of governments and community organizations to overcome the tendency for underinvestment that such geographic externalities are likely to generate.

\section{APPENDIX: GMM ESTIMATION OF THE MICRO GROWTH MODEL}

The estimation procedure entails stacking the equations in (8) to form a system, with one equation for each year. For $T=6$, the system of equations to be estimated is as follows:

$$
\begin{aligned}
& q_{3}\left(\Delta c_{i 3}, x_{i 3}, z_{i}, b_{3}\right)=\bar{u}_{i 3} \\
& q_{4}\left(\Delta c_{i 4}, x_{i 4}, z_{i}, b_{4}\right)=\bar{u}_{i 4} \\
& q_{5}\left(\Delta c_{i 5}, x_{i 5}, z_{i}, b_{5}\right)=\bar{u}_{i 5} \\
& q_{6}\left(\Delta c_{i 6}, x_{i 6}, z_{i}, b_{6}\right)=\bar{u}_{i 6}
\end{aligned}
$$

In these equations, $\overline{\mathbf{u}}_{\mathbf{i} \mathbf{t}}(t=3,4,5,6)$ is the error term $u_{i t}-r_{t} u_{i t-1}, x_{i t}$ is the vector of timevarying explanatory variables, $z_{i}$ the vector of time invariant variables, and $\mathbf{b}_{\mathbf{t}}=\left[\alpha, \beta, \xi, \gamma, r_{t}\right]$ is the parameter vector. Note that not all the b's vary with time, implying certain cross-equation restrictions on the parameters. It is convenient to write the model in the compact form:

$$
q\left(\Delta c_{i}, x_{i}, z_{i}, b\right)=\overline{\mathbf{u}}_{\mathbf{i}}
$$

where $\overline{\mathbf{u}}_{i}=\left[\bar{u}_{i 3}, \bar{u}_{i 4}, \bar{u}_{i 5}, \bar{u}_{i 6}\right]^{\prime}$ is a $(T-2) \times 1$ vector for household $i$.

The GMM procedure estimates the parameters $\mathbf{b}_{\mathbf{t}}$ by minimizing the criterion function:

$$
Q_{N T}(b)=g_{N}(b)^{\prime} A_{N}^{-1} g_{N}(b)
$$

where the $(l \times l)$ weighting matrix $A_{N}$ is positive definite, and where the $(l \times 1)$ vector of sample orthogonality conditions is given by:

$$
g_{N}(b)=\left[\sum_{i=1}^{N} w_{i}^{\prime} q\left(\Delta c_{i}, x_{i}, z_{i}, b\right)\right]
$$

where $w_{i}$ is a $((T-2) \times l)$ vector of $l$ instruments. Heteroscedasticity is likely to exist across the cross-sections. We use White's approach to correct for this. The optimal weighting matrix is thus the inverse of the asymptotic covariance matrix:

$$
A_{N}=\left[\sum_{i=1}^{N} w_{i}^{\prime} \hat{u}_{i} \hat{u}_{i}^{\prime} w_{i}\right]
$$

where $\hat{\mathbf{u}}_{\mathbf{i}}$ is the vector of the estimated residuals. These GMM estimates yield parameter estimates that are robust to heteroscedasticity.

The first-order conditions of minimizing the non-linear equation $Q_{N T}(\mathbf{b})$ does not provide us with an explicit solution. We must thus use a numerical optimization routine to solve for $\hat{\mathbf{b}}$. All the computations can be done using standard software such as EVIEWS and GAUSS. 


\section{ACKNOWLEDGEMENTS}

The assistance and advice provided by staff of China's State Statistical Bureau in Beijing and at various provincial and county offices are gratefully acknowledged. For useful comments and discussions we thank the Journal's two anonymous referees, Francisco Ferreira, Karla Hoff, Aart Kraay, Kevin Lang, Marc Nerlove, Jaesun Noh, Danny Quah, Anand Swamy, and seminar participants at the World Bank, University of Maryland College Park, Boston University, George Washington University, Université des Sciences Sociales, Toulouse, the MacArthur Foundation/World Bank Workshop on Emerging Issues in Development Economics, and the fifth LACEA conference in Rio De Janerio. The financial support of the World Bank's Research Committee (under RPO 681-39) is also gratefully acknowledged. These are the views of the authors, and should not be attributed to the World Bank.

\section{REFERENCES}

Ahn SC, Lee YH, Schmidt P. 1994. GMM estimation of a panel data regression model with time-varying individual effects. Mimeo, Arizona State University.

Ahn SC, Schmidt P. 1995. Efficient estimation of models for dynamic panel data. Journal of Econometrics 68: $5-27$.

Arellano M, Bond S. 1991. Some tests of specification for panel data: Monte Carlo evidence and an application to employment equation. Review of Economic Studies 58: 277-298.

Bhargava A, Sargan JD. 1983. Estimating dynamic random effects models from panel data covering short time periods. Econometrica 51: 1635-1659.

Binder M, Hsiao C, Hashem Pesaran M. 2000. Estimation and inference in short panel vector autoregressions with unit roots and cointegration. Bank of Spain Working Paper \#0005, Madrid, Spain.

Blundell R, Bond S. 1997. Initial conditions and moment restrictions in dynamic panel data models. University College London Discussion Paper Series \#97/07, London, University College.

Borjas G. 1995. Ethnicity, neighborhoods, and human capital externalities. American Economic Review 85 : $365-380$.

Chamberlain G. 1984. Panel data. In Handbook of Econometrics (Vol. 2), Grilliches Z, Intrilligator M (eds.) North-Holland: Amsterdam.

Chen S, Ravallion M. 1996. Data in transition: assessing rural living standards in southern China. China Economic Review 7: 23-56.

Das Gupta M. 1987. Informal security mechanisms and population retention in rural India. Economic Development and Cultural Change 36: 101-120.

Davies RB. 1977. Hypothesis testing when a nuisance parameter is unidentified under the alternative. Biometrika 64: 247-254.

Davies RB. 1987. Hypothesis testing when a nuisance parameter is unidentified under the alternative. Biometrika 74: 33-43.

Godfrey LG. 1988. Misspecification Tests in Econometrics. Cambridge University Press: Cambridge.

Hall A. 1993. Some aspects of generalized method of moments estimation. In Handbook of Statistics. (Vol. 11), Maddala GS, Rao CR, Vinod HD (eds). North-Holland: Amsterdam.

Holtz-Eakin D, Newey W, Rosen H. 1988. Estimating vector autoregressions with panel data. Econometrica 56: $1371-1395$.

Howes S, Hussain A. 1994. Regional growth and inequality in rural China. Working Paper EF 11, London School of Economics.

Jalan J, Ravallion M. 1998. Are there dynamic gains from a poor-area development program?. Journal of Public Economics 67: 65-85.

Knight J, Song L. 1993. The spatial contribution to income inequality in rural China. Cambridge Journal of Economics 17: 195-213.

Leading Group. 1988. Outlines of Economic Development in China's Poor Areas. Office of the Leading Group of Economic Development in Poor Areas Under the State Council, Agricultural Publishing House, Beijing.

Copyright $\odot 2002$ John Wiley \& Sons, Ltd.

J. Appl. Econ. 17: 329-346 (2002) 
Lyons T. 1991. Interprovincial disparities in China: output and consumption, 1952-1987. Economic Development and Cultural Change 39: 471-506.

Ogaki M. 1993. Generalized method of moments: econometric applications. In Handbook of Statistics, Vol. 11, Maddala GS, Rao CR, Vinod HD (eds). North-Holland: Amsterdam.

Ramsey F. 1928. A mathematical theory of saving. Economic Journal 38: 543-559.

Ravallion M, Jalan J. 1996. Growth divergence due to spatial externalities. Economics Letters 53: 227-232.

Ravallion M, Jalan J. 1999. China's lagging poor areas. American Economic Review (Papers and Proceedings) 89: 301-305.

Ravallion M, Wodon Q. 1999. Poor areas, or only poor people?. Journal of Regional Science 39: 689-711.

Romer PM. 1986. Increasing returns and long-run growth. Journal of Political Economy 94: 1002-1037.

Rozelle S. 1994. Rural industrialization and increasing inequality: emerging patterns in China's reforming economy. Journal of Comparative Economics 19: 362-391.

Tsui KY. 1991. China's regional inequality, 1952-1985. Journal of Comparative Economics 15: 1-21.

World Bank. 1992. China: Strategies for Reducing Poverty in the 1990s. World Bank: Washington, DC.

World Bank. 1997. China 2020: Sharing Rising Incomes. World Bank: Washington, DC. 